\title{
PHONOLOGICAL PROCESSES IN PORTUGUESE CHILDREN WITH SPEECH SOUND DISORDERS
}

\author{
LUIS M. T. JESUS \\ University of Aveiro \\ lmtj@ua.pt \\ DIANA DOMINGUES \\ University of Aveiro
}

\author{
MARISA LOUSADA \\ University of Aveiro
}

\author{
ANDREIA HALL
}

University of Aveiro

\author{
DAVID TOMÉ \\ Polytechnic Institute of Porto
}

\begin{abstract}
This study investigates the nature of phonological impairment in 20 pre- and earlyschool Portuguese children with phonologically based Speech Sound Disorders (SSD). The phonological profile of these children was compared with the performance of 232 younger typically developing (TD) controls. Results showed differences in phonological acquisition of children with phonologically based SSD, namely a low percentage of correct consonants score and a higher percentage of occurrences of typical phonological processes. Children with phonologically based SSD also used phonological processes (e.g., backing and initial consonant deletion) that are considered unusual in normally developing children and were not observed in the TD group. Results for SSD children also showed that early acquisition consonants were substituted by later acquisitions. Children with SSD presented differences in phonological acquisition, unusual phonological processes, and replaced early acquisition consonants by later acquisition consonants. This knowledge is useful for speech and language therapists in the diagnosis and treatment of SSD.
\end{abstract}

Keywords: Speech sound disorders; phonological processes; children; Portuguese.

\section{Introduction}

Children with phonologically based speech sound disorders (SSD) are one of the largest groups of children referred to Speech and Language Therapy services (Joffe 2008; Oliveira et al. 2015). The phonological component is part of a syn- 
ergic symbolic system (language) used by humans to communicate. According to the Theory of Phonology as Human Behaviour (Tobin 2009a, 2009b), the organisation and development of phonology tends to respond to a synergetic compromise in the struggle to achieve maximum communication with minimal effort. This theory has four underlying factors that are relevant to explain the operation and acquisition of phonological systems (Tobin 2009b): communication factor; physiology of vocal tract; acoustic medium; human factor. It therefore gives focus to aspects like the orofacial skills to control the production of phonemes, the human capacity to perceive them, and other human skills like intelligence and memory capacity. These are therefore key issues when the phonological component is analysed, both in typical and atypical development.

Although children with SSD constitute a heterogeneous group, most of them show some degree of difficulty in their speech production, that is manifested by a low percentage of correct consonants (PCC) and the use of many simplification processes (Beers 1992; Bortolini and Leonard 2000; Crosbie et al. 2005; Dodd et al. 2003; Dodd 2014; Lousada et al. 2013; Maillart and Parisse 2006; Mediavilla et al. 2002; Roberts et al. 1998; Yavas and Lamprecht 1988). Most of them present these phonological impairments with no obvious cause. Recent studies have been investigating the possible underlying causes of SSD in this group of children without any apparent sensory, structural, neurological or psychological impairment. Some studies revealed the existence of differences in the brain structures in areas related to the production and perception of speech (Preston et al. 2014), and even, in patterns of brain activation that suggests a deficit in phonological memory and in speech perception (Tkach et al. 2011).The majority of these phonological processes signal a delay in development, because they occur in the early stages of normally developing children, but unusual patterns have also been noted (Beers 1992; Mediavilla et al. 2002; Yavas and Lamprecht 1988). The following phonological processes have been found to occur in typically developing (TD) children in different languages (Bowen 2009; Dodd et al. 2003; Tobin 2009b), including Portuguese (Castro et al. 1999; Guerreiro and Frota 2010; Lousada 2012), and are therefore referred to as typical phonological processes (Ingram 1976): fronting (e.g. / ke' fe/ 'coffee' produced as [te'fe]); stopping (e.g. /'fake/ 'knife' produced as ['pake]); depalatalization (e.g. /'Savi/ 'key' produced as ['savi]); palatalization (e.g. /se'patu/ 'shoe' produced as [ $\int^{\mathrm{e}}$ patu]); devoicing of fricatives (e.g. /'kaze/ 'house' produced as ['kase]); final consonant deletion (e.g. /ku'mer/ 'to eat' produced as [ku'me]); cluster reduction (e.g. /'tre // 'three' produced as ['tef]); gliding of liquids (e.g. /'bole/ 'ball' produced as ['bowe]); week syllable deletion (e.g. /'bole/ 'ball' produced as ['bo]). The same processes have been found to occur in chil- 
dren with phonologically based SSD (Beers 1992; Bortolini and Leonard 2000; Fee 1995; Mediavilla et al. 2002; Roberts et al. 1998; Yavas and Lamprecht 1988), and when they occur at later stages of development they are referred to as delayed phonological processes. Children with SSD also use some less common processes tha in TD children (Beers 1992; Mediavilla et al. 2002) such as initial consonant deletion (e.g. /'patu/ 'duck' produced as ['atu]) (Miccio and Scarpino 2008). Studies of Brazilian SSD children (Wertzner 2000; Yavas and Lamprecht 1988) suggest that they usually present typical (e.g. cluster reduction, final consonant deletion, fronting, and palatalization) and also unusual processes (e.g. devoicing of stops, intervocalic liquid nasalization).

There have (only) been a few studies on phonological processes in Portuguese children (Castro et al. 1999b; Guerreiro and Frota 2010; Lousada et al. 2012; Lousada et al. 2013). None of them compare the processes used by disordered children to those used by TD children. Lousada et al. (2012) studied the ages of suppression of phonological processes in 768 Portuguese children between $3 ; 0$ and $6 ; 11$ years of age. The ages of suppression of phonological processes were defined as the age at which $85 \%$ of children in the sample made zero errors in each process (Khan and Lewis 2002). Table 1 shows the ages at which $85 \%$ of the sample (i.e., $\mathrm{N}=768$ ) produced zero errors in each process.

Table 1. Age group at which $85 \%$ of Portuguese children produce zero errors for each phonological process. Adapted from Lousada et al. (2012).

\begin{tabular}{ll}
\hline Phonological processes & Age group \\
\hline Fronting & $3 ; 0-3 ; 5$ \\
Stopping & $3 ; 0-3 ; 5$ \\
Depalatalization & $4 ; 0-4 ; 5$ \\
Palatalization & $4 ; 0-4 ; 5$ \\
Devoicing of fricatives & $5 ; 0-5 ; 5$ \\
Final consonant deletion & $6 ; 6-6 ; 11$ \\
Cluster reduction & $6 ; 6-6 ; 11$ \\
Gliding of liquid & $6 ; 6-6 ; 11$ \\
Weak syllable deletion & $>6 ; 6-6 ; 11$ \\
\hline
\end{tabular}


The principal aim of this study was to describe and compare the phonological skills of 20 pre- or early school-aged children with phonologically based SSD and 232 TD children with ages 3;0 to 4;11. More specifically, whether phonologically based SSD children presented only a delay in phonological acquisition (use the same phonological processes of TD children but with a delay) or a disorder (use unusual phonological processes).

2. Method

\subsection{Participants}

A group of 20 Portuguese children ( 15 boys, 5 girls) with phonologically based SSD, aged $3 ; 8$ to $6 ; 7$, were recruited through local speech and language therapists (SLTs). Prior to the start of the project, they were diagnosed as having phonologically based SSD, after extensive assessment by a Speech and Language Therapist (SLT), an audiologist and a psychologist. Participant selection criteria included: greater than 1.5 standard deviation below the mean on a standardised language test (Kay and Tavares 2008); audition of $20 \mathrm{~dB}$ or lower in the frequencies $500 \mathrm{~Hz}, 1000 \mathrm{~Hz}$ and $2000 \mathrm{~Hz}$; an absence of social or emotional problems; no obvious neurological damage. Children diagnosed with inconsistent phonological disorder or diagnosed with childhood apraxia of speech were excluded. Non-verbal ability (NVIQ) was assessed with the Performance Scale of the Wechsler Preschool and Primary Scale of Intelligence - Revised (WPPSI-R) (Wechsler 2003). NVIQ ranged from 62 to 117 (mean 89.7; standard deviation 19.1). All ethical procedures were ensured and informed consent was collected from all carers prior to any data collection.

A group of 232 children (116 boys; 116 girls) served as controls. These children were developing normally and were younger (ages ranged from $3 ; 0$ to 4;11) (Lousada et al., 2012) than the disordered children. Four subgroups were created (one for each age group, six months wide) and the PCC mean was calculated for each subgroup.

There was a large difference within the disordered children group in PCC values (from $16.0 \%$ to $73.8 \%$ ), so two subgroups were created: the first subgroup $(\mathrm{N}=9)$ had a PCC above $50 \%(61.3 \pm 8.1 \%)$ and the second subgroup $(\mathrm{N}=11)$ had a PCC below $50 \%(29.1 \pm 11.9 \%)$. A criterion of $50 \%$ was used since this is the cut-off to distinguish levels of severity of the disorder (children with a PCC above $50 \%$ are considered to have a severe disorder; Shriberg and Kwiatkowski 1982). 


\subsection{Assessments}

The children's phonological abilities were assessed with 67 single words (naming task) through a standardised Portuguese phonetic-phonological test (Lousada et al. 2012; Mendes et al. 2013). This instrument provides the context to test and analyse all sounds in different word positions and also includes a phonological processes analysis. This procedure took an average duration of 20 minutes. Recordings were made in a sound-treated room at the Speech, Language and Hearing Laboratory (SLHlab), University of Aveiro, Portugal. The acoustic signal was recorded using a Cirrus Research acoustic free field MK224 microphone located $1 \mathrm{~m}$ in front of the speaker's mouth and pre-amplified (Cirrus Research MV $181 \mathrm{~A}$ ), then amplified and filtered by a Cirrus Research ZE 901B Preamplifier Power Supply, and finally recorded to a Marantz PMD671 Solid State Recorder with a sampling frequency of $48 \mathrm{kHz}$ and 16 bits.

\subsection{Data Analysis}

The percentage of errors due to each process (cluster reduction, final consonant deletion, devoicing of fricatives, weak syllable deletion, gliding of liquids, stopping, fronting, depalatalization, palatalization, backing, and initial consonant deletion) was calculated for all children. These data were then subjected to a statistical analysis, using IBM SPSS Statistics 19, to compare the study and control groups.

First, for each phonological process and for the TD children, a one-way Analysis-of-Variance (ANOVA) was performed to assess differences between the 4 age subgroups considered: $[3 ; 0-3 ; 6[;[3 ; 6-4 ; 0[;[4 ; 0-4 ; 6 ; 0[;[4 ; 6-5 ; 0[$. Based on the homogenous subsets obtained through Tuckey's multiple comparisons tests, the 4 age subgroups were regrouped into new (less) non-overlapping subgroups. Then, for each process and for the study group, a Mann-Whitney test was performed to assess differences between the two subgroups considered.

Finally, using the new subgroups obtained for the TD children, a nonparametric ANOVA (Kruskal-Wallis test) was performed and multiple comparisons were made (using Bonferroni's correction) for each of the two study subgroups with each of the control subgroups.

The choice of a parametric ANOVA in the first step was based on the size of the control group and a balanced design. The choice of nonparametric tests for the remaining comparisons was based on the small study group size and the asymmetric nature of most of the sample distributions. 


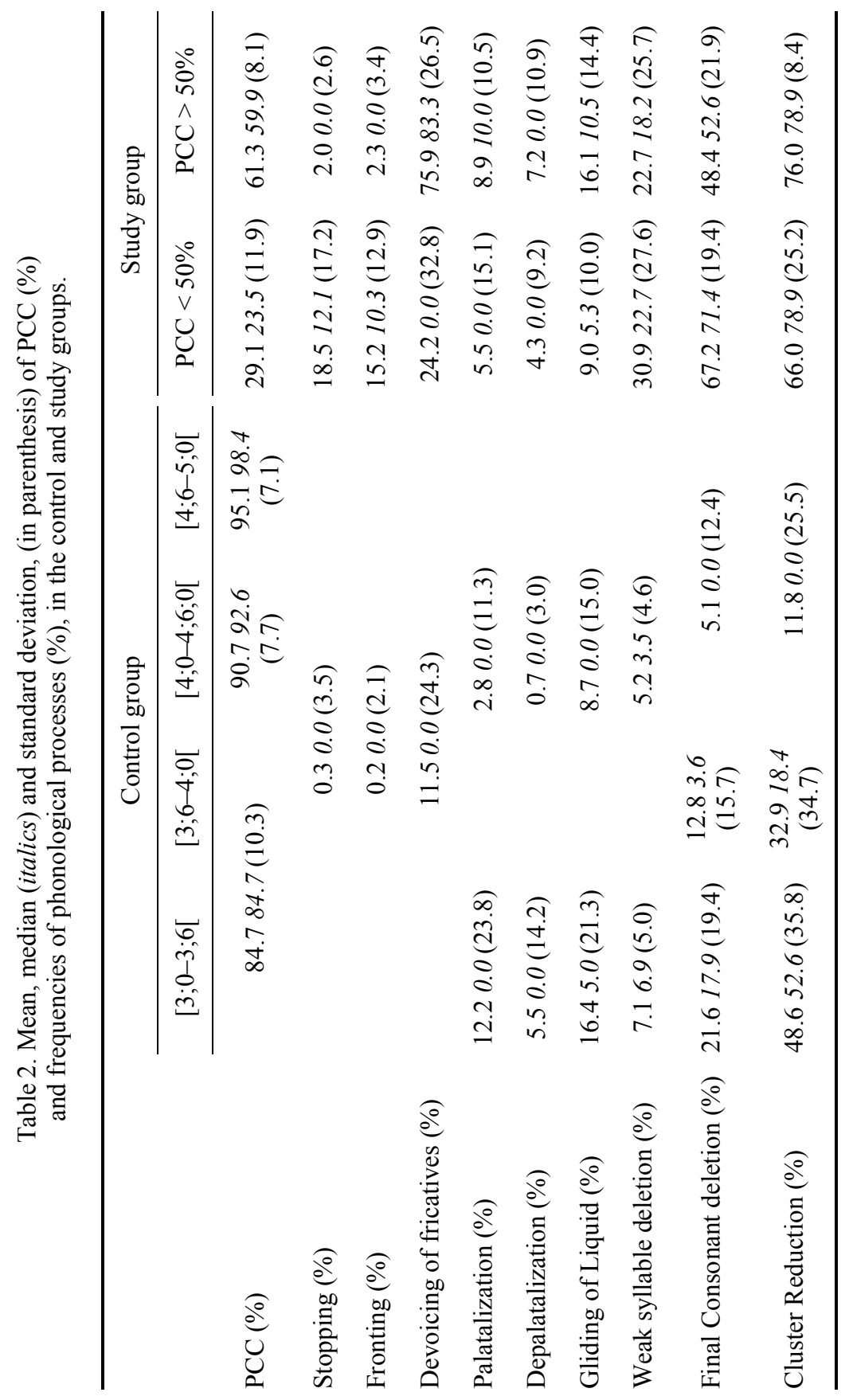




\section{Results and discussion}

Table 2 shows the mean, median and std. deviation of all the subgroups considered in this study. The control subgroups considered in Table 2 are the ones obtained after performing a one-way ANOVA for each variable and grouping the homogeneous (and non-overlapping) subgroups accordingly (see Table 3). Based on the new subgroups presented in Table 2, we can see that, except for stopping, fronting and devoicing of fricatives, all processes revealed significant differences between the four TD subgroups (see Table 3). Furthermore, none of the processes showed that all the four TD subgroups were significantly different between each other (see Table 3). Thus, for all processes some sort of regrouping was performed (see Table 2). This means that the considered processes either showed no significant differences through the whole age interval, or showed no significant differences through part of the age interval.

The p-values of the Mann-Whitney tests performed over the two study subgroups, for each process, are also presented in Table 3. As can be seen five of the processes did not reveal significant differences between the two subgroups. Due to the small sample size of these groups and consequent power reduction, some eventual differences did not show. It is also very likely that the differences between the two subgroups were determined by the prevalence of atypical processes (see paragraphs below).

Table 3. p-values of the parametric one way ANOVA for the control group (factor age with 4 levels $-[3 ; 0-3 ; 6[;[3 ; 6-4 ; 0[;[4 ; 0-4 ; 6 ; 0[;[4 ; 6-5 ; 0[)$ and the Mann Whitney U tests for the study group (groups PCC $<50 \%$ and $\mathrm{PCC}>50 \%$ ).

\begin{tabular}{lcc}
\hline & Control group & Study group \\
\hline PCC & $0.000^{*}$ & - \\
Stopping & 0.435 & $0.000^{*}$ \\
Fronting & 0.428 & $0.012^{*}$ \\
Devoicing of fricatives & 0.230 & $0.001^{*}$ \\
Palatalization & $0.002^{*}$ & 0.147 \\
Depalatalization & $0.003^{*}$ & 0.727 \\
Gliding of Liquid & $0.012^{*}$ & 0.298 \\
Weak syllable deletion & $0.014^{*}$ & 0.334 \\
Final Consonant deletion & $0.000^{*}$ & $0.026^{*}$ \\
Cluster Reduction & $0.000^{*}$ & 0.641 \\
\hline
\end{tabular}

* Significant at the $5 \%$ level. 
The Kruskal-Wallis tests performed for all the considered processes in this paper revealed significant differences between the subgroups (control and study). Results of the multi-comparison tests are shown in Table 4.

Table 4. p-values of the Mann Whitney U tests.

\begin{tabular}{|c|c|c|c|c|c|c|c|c|}
\hline & \multicolumn{4}{|c|}{$\mathrm{PCC}<50 \%$} & \multicolumn{4}{|c|}{$\mathrm{PCC}>50 \%$} \\
\hline & $\begin{array}{l}\overrightarrow{0} \\
\ddot{m} \\
\dot{p} \\
\dot{m}\end{array}$ & $\begin{array}{l}\text { O्. } \\
\dot{+} \\
\dot{b} \\
\dot{v}\end{array}$ & $\begin{array}{l}0 \\
\dot{0} \\
\dot{+} \\
\dot{0} \\
\dot{\theta}\end{array}$ & $\begin{array}{l}\dot{0} \\
\ddot{n} \\
\dot{b} \\
\dot{d}\end{array}$ & $\begin{array}{l}\overrightarrow{0} \\
\dot{m} \\
\dot{p} \\
\dot{n}\end{array}$ & $\begin{array}{l} \\
\dot{+} \\
\dot{0} \\
\dot{\varphi} \\
\end{array}$ & $\begin{array}{l}\dot{0} \\
\dot{0} \\
\dot{+} \\
\dot{1} \\
\dot{ \pm}\end{array}$ & $\begin{array}{l}\dot{0} \\
\dot{n} \\
\dot{b} \\
\dot{v}\end{array}$ \\
\hline PCC & & & $0.000^{*}$ & $0.000^{*}$ & & & $0.000^{*}$ & $0.000^{*}$ \\
\hline Stopping & \multicolumn{4}{|c|}{$0.000^{*}$} & \multicolumn{4}{|c|}{$0.000 *$} \\
\hline Fronting & \multicolumn{4}{|c|}{$0.000^{*}$} & \multicolumn{4}{|c|}{$0.000 *$} \\
\hline $\begin{array}{l}\text { Devoicing of } \\
\text { fricatives }\end{array}$ & \multicolumn{4}{|c|}{0.320} & \multicolumn{4}{|c|}{$0.000 *$} \\
\hline Palatalization & \multicolumn{2}{|c|}{1.000} & \multicolumn{2}{|c|}{1.000} & & & \multicolumn{2}{|c|}{$0.004 *$} \\
\hline Depalatalization & \multicolumn{2}{|c|}{1.000} & \multicolumn{2}{|c|}{0.052} & & & \multicolumn{2}{|c|}{$0.024 *$} \\
\hline $\begin{array}{l}\text { Gliding of } \\
\text { Liquid }\end{array}$ & \multicolumn{2}{|c|}{1.000} & \multicolumn{2}{|c|}{0.676} & & & \multicolumn{2}{|c|}{$0.036^{*}$} \\
\hline $\begin{array}{c}\text { Weak syllable } \\
\text { deletion }\end{array}$ & \multicolumn{2}{|c|}{$0.004 *$} & \multicolumn{2}{|c|}{$0.000 *$} & & & \multicolumn{2}{|c|}{$0.008^{*}$} \\
\hline $\begin{array}{c}\text { Final Consonant } \\
\text { deletion }\end{array}$ & \multicolumn{2}{|c|}{$0.000 *$} & $0.000^{*}$ & $0.000^{*}$ & \multicolumn{2}{|c|}{$0.000^{*}$} & $0.000^{*}$ & $0.000 *$ \\
\hline $\begin{array}{l}\text { Cluster } \\
\quad \text { Reduction }\end{array}$ & \multicolumn{2}{|c|}{1.000} & $0.024 *$ & $0.000^{*}$ & \multicolumn{2}{|c|}{0.660} & $0.018^{*}$ & $0.000^{*}$ \\
\hline
\end{tabular}

* Significant at the $5 \%$ level.

All together, the results showed that children with SSD exhibit considerably lower PCC values than younger children with normal development (even when compared with TD children aged 3;0). Significant differences were obtained for both subgroups when compared to any of the control age groups (see Table 4, row 3 ). This reveals a lower precision in consonant production, taking into account the target words children with SSD were trying to produce. 
A number of phonological processes (Costa 2010; Freitas 1997; Guerreiro and Frota 2010; Lousada et al. 2012), typical for European Portuguese (EP), were also analysed in order to investigate the nature of the errors that contributed to the low values of the PCC parameter. It was shown that the stopping and fronting processes are no longer produced by 3 -year-old TD children. These processes are typical processes of early stages of phonological development (Costa 2010; Lousada et al. 2012). Children with SSD showed higher frequency of occurrence of these processes, leading to significant differences among the groups (see Table 4, rows 4 and 5). Within the SSD group, the subgroup with PCC $<50 \%$ was the one which displayed the highest frequency of occurrence because these children are still in an early stage of phonological development.

Analysis of phonological processes in fricatives (devoicing, palatalization and depalatalization) revealed that the only process for which there were no significant differences between the control subgroups was devoicing of fricatives. This process is in fact the most frequent and persistent fricative error pattern observed in Portuguese children (Castro et al. 1999; Guerreiro and Frota 2010). Hence, for this process, the control group was considered with no division into subgroups as can be seen in both Tables 3 and 5. The other processes (palatalization and depalatalization) suffered a significant reduction between the ages of 3;4 and 4;5, and therefore led to a regrouping into two subgroups as shown in both Tables 3 and 5 (rows 7 and 8). For these processes, a common pattern was observed in the study subgroups: the children with PCC $>50 \%$ exhibited higher occurrence frequencies (see Table 2), but the differences between the two subgroups were not significant (last column of Table 3), probably due to the small sample size, which leads to a reduction in the test power. Looking at the descriptive statistics in Table 2 the devoicing of fricatives process stands out, by presenting an $83.3 \%$ median for the PCC $>50 \%$ subgroup against a $0.0 \%$ median for the $\mathrm{PCC}<50 \%$ subgroup. This difference between the subgroups is due to the fact that many PCC $<50 \%$ subgroup children do not yet produce fricative consonants, and use processes such as stopping or syllable deletion but not devoicing of fricatives. Therefore, the only observed significant differences occurred between the PCC $>50 \%$ group and the whole control group for the $d e-$ voicing of fricatives process, and for the $[4 ; 0-5 ; 0$ [ control subgroup for the processes palatalization and depalatalization, since at this age, a reduction in the processes occurrence is observed in TD children. The inexistence of significant differences between the PCC $<50 \%$ subgroup and the $[4 ; 0-5 ; 0$ [ group, in the depalatalization process, was probably due to the Bonferroni correction (without the correction the difference would have been significant, and even with the correction the p-value is 0.052 ). Looking at the descriptive statistics it could be 
seen that this process still occurred in the $\mathrm{PCC}<50 \%$ subgroup, and was almost inexistent for $[4 ; 0-5 ; 0[$ TD children.

A similar behaviour for the gliding of liquid process was observed, with the PCC $>50 \%$ subgroup having higher frequency. For the control group, a difference between the age groups $[3 ; 0-4 ; 0[$ and $[4 ; 0-5 ; 0[$ was observed (see the groups in Table 2). Comparatively to the other two processes (palatalization and depalatalization), a higher frequency for gliding of liquid in the control group was observed. This observation agrees with what has been shown in the literature, i.e., this process tends to be, among all substitution processes, the most observed and persistent in TD children (Dodd et al. 2003; Guerreiro and Frota 2010; Lousada et al. 2012). For this process, the only significant differences observed were between the PCC $>50 \%$ subgroup and the age range $[4 ; 0-5 ; 0[$, with the study subgroup exhibiting a higher frequency, which is similar to the one identified for the control age group [3;0-4;0[. Again, the PCC $<50 \%$ subgroup did not display significant differences when compared to the control subgroups. The lower frequency in this study group was due to the fact that these children produced other error patterns of liquids, characteristic of earlier stages (like the initial consonant deletion of liquids, e.g., ['bor] rather than ['bowe] for the word /'bole/ 'ball').

The syllabic structure processes constitute, together with the devoicing of fricatives process for the $\mathrm{PCC}>50 \%$ group, the most prevalent processes in the SSD children. Both study subgroups (PCC $<50 \%$ and $\mathrm{PCC}>50 \%$ ) showed average occurrence percentages (for the processes weak syllable deletion and final consonant deletion) which were significantly higher than any of the control subgroups. These results corroborate other studies that identify the existence, in this population, of a greater difficulty with coda consonant production, as well as in processing segments less salient, like the unstressed syllables (Bortolini and Leonard 2000; Maillart and Parisse 2006; Mediavilla et al. 2002).

The cluster reduction process was the syllabic structure process produced with highest frequency both by children with SSD and TD children, which agrees with the fact that complex syllabic structures (such as CCV) are acquired at later stages (Castro et al. 1999; Fee 1995; Guerreiro and Frota 2010; Lousada et al. 2012). However, this process occurred more frequently in the study group children, particularly when compared to the control subgroup $[4 ; 0-5 ; 0[$, since during this age interval a decrease in the occurrence of this process is observed within the typical developing population. Complex syllabic structures acquisition is therefore especially hard for children with SSD.

The production of atypical processes was also observed in SSD children. Atypical error patterns are defined as patterns that occur in less than $10 \%$ of the 
TD population (Dodd et al. 2003). In the study group the following atypical processes were observed: initial stop consonant deletion, observed in 10 children with PCC $<50 \%-23.0 \%( \pm 25.7 \%)$ and in 5 children with PCC $>50 \%-$ $19.6 \%$ ( $\pm 26.0 \%)$; backing in dental and labiodentals consonants, which was observed in both study subgroups with average occurrence of $7.0 \%( \pm 10.3 \%)$ and $8.4 \%( \pm 7.0 \%)$ for the PCC $<50 \%$ subgroup, and $1.3 \%( \pm 1.9 \%)$ and $11.1 \%$ $( \pm 20.2 \%)$ for the PCC $>50 \%$ subgroup, respectively. The bilabial backing is an atypical process that only occurred in the PCC $<50 \%$ subgroup, with an average of $9.6 \%( \pm 11.4 \%)$.

Other atypical substitutions also occurred, for example, the substitution of early acquisition consonants (stops and nasals) by other consonants (liquids and trills), usually acquired at later stages (e.g., /'dedu/ 'finger' produced as ['reru]). This evidence agrees with results presented in Mediavilla et al. (2002), identifying that children with SSD were less accurate in the production of sounds acquired in early stages (stops and nasals), which suggests that there is a "plateaux" in early acquisitions, with the appearance of later acquisition consonants.

The initial stop consonant omission is considered atypical because in this position the consonants have a more communicative force (Tobin 2009b), so normally children preserve them in their speech. In typical development the substitution of non-apical consonants by apical ones duo to greater flexibility and control of the tongue's apex, is also observed (Tobin 2009b). So for this reason the backing process observed in children with SSD is considered atypical. Atypical speech sound errors in SSD may reflect an impairment in higher linguistic representation level, namely in how phonological information is processed and organised (Preston et al. 2013). So, the occurrence of the atypical processes in children with SSD may be related to deficits in speech perception, which are confirmed in recent studies as underpinning this disorder. Therefore, children with SSD have greater difficulties to perceive fast and short sounds, like stops, even in positions with more communicative information (like initial position). In addition, it is important to note that children with SSD do not have oral-motor impairments, so they have articulatory maturation to produce more complex sounds, like fricatives and liquids. This may also explain the occurrence of atypical substitutions like liquids replacing stops.

According to the longitudinal study of Preston et al. (2013) the occurrence of atypical processes in SSD predict long-term phonological awareness difficulties and, consequently, in acquisition of literacy skills. Therefore the identification and analysis of the atypical processes occurrence will be important for the establishment of a prognosis. 


\section{Conclusions}

The results suggest that children with phonologically based SSD have a lower PCC score and a greater use of typical phonological processes when compared with TD children. Children with SSD also use atypical phonological processes such as initial stop consonant deletion and backing that are not observed in the control group. Results for SSD children also show that early acquisition consonants are substituted by later acquisition consonants, which suggest that these children have a speech disorder.

The knowledge of which phonological processes are used by children with SSD (typical and unusual) is useful for SLTs in the early identification of these children, to diagnose the subtype of speech impairment and to plan treatment.

\section{REFERENCES}

Beers, M. 1992. "Phonological processes in Dutch language impaired children". Logopedics Phoniatrics Vocology 17. 9-16.

Bortolini, U. and L. Leonard. 2000. "Phonology and children with specific language impairment: Status of structural constraints in two languages". Journal of Communication Disorders 33. 131-150.

Bowen, C. 2009. Children's speech sound disorders. Oxford: Wiley-Blackwell.

Castro, S.L., S. Neves, I. Gomes and S. Vicente. 1999. "The development of articulation in European Portuguese: A cross-sectional study of 3- to 5-years-olds naming pictures". In: Pinto, M. G., J. Veloso and B. Maia (eds.), 5th International Congress of the International Society of Applied Psycholinguistics. Porto: Faculdade de Letras da Universidade do Porto.

Costa, T. 2010. The acquisition of the consonantal system in European Portuguese: Focus on place and manner features. (M.Sc. thesis, Universidade de Lisboa, Lisbon.)

Crosbie, S., A. Holm and B. Dodd. 2005. "Intervention for children with severe speech disorder: A comparison of two approaches". International Journal of Language \& Communication Disorders 40(4). 467-491. 
Dodd, B. 2014. "Differential diagnosis of Pediatric Speech Sound Disorder". Current Developmental Disorders Reports 1(3). 189-196.

Dodd, B., A. Holm, Z. Hua and S. Crosbie. 2003. "Phonological development: A normative study of British English-speaking children". Clinical Linguistics \& Phonetics 17(8). 617-643.

Fee, E.J. 1995. "The phonological system of a specifically language-impaired population". Clinical Linguistics \& Phonetics 9(3). 189-209.

Freitas, M.J. 1997. Aquisição da Estrutura Silábica do Português Europeu. (PhD dissertation, Universidade de Lisboa, Lisbon.)

Guerreiro, H. and S. Frota. 2010. "Os processos fonológicos na fala da criança de cinco anos: tipologia e frequência”. Cadernos de saúde 3. 57-72.

Ingram, D. 1976. Phonological disability in children. London: Edward Arnold.

Joffe, V. 2008. "Minding the gap in research and practice in developmental language disorders". In: Joffe, V., M. Cruice and S. Chiat (eds.), Language disorders in children and adults: New issues in research and practice. Oxford: WileyBlackwell. 68-97.

Kay, E. and D. Tavares. 2008. Teste de avaliação da linguagem na criança. (5th ed.) Lisboa: Oficina Didáctica.

Khan, L. and N. Lewis. 2002. Khan-Lewis phonological analysis manual. Minneapolis: American Guidance Service.

Lousada, M. 2012. Alterações Fonológicas em Crianças com Perturbação de Linguagem [The Phonological Abilities of (Problems in) Children With Language Impairment: The Nature of Phonological Disorder and Effectiveness of Intervention]. (PhD dissertation, University of Aveiro.)

Lousada, M., L.M.T. Jesus, S. Capelas, C. Margaça, D. Simões, A.R. Valente, A. Hall and V.L. Joffe. 2013. "Phonological and articulation treatment approaches in Portuguese children with speech and language impairments: A randomised controlled intervention study". International Journal of Language \& Communication Disorders 48(2). 172-187.

Lousada, M., A.P. Mendes, A.R. Valente and A. Hall. 2012. "Standardization of a Phonetic-Phonological Test for European Portuguese Children”. Folia Phoniatrica et Logopaedica 64(3). 151-156.

Maillart, C. and C. Parisse. 2006. "Phonological deficits in French speaking children with SLI". International Journal of Language \& Communication Disorders 41(3). 253-274.

Mediavilla, E., M. Torrent and M. Raventós. 2002. "A comparative study of the phonology of pre-school children with specific language impairment (SLI), language delay (LD) and normal aquisition”. Clinical Linguistics \& Phonetics 16(8). 573-596.

Mendes, A., E. Afonso, M. Lousada and F. Andrade. 2013. Teste Fonético-Fonológico $A L P E$. Aveiro: Edubox.

Miccio, A.W. and S.E. Scarpino. 2008. "Phonological analysis, phonological processes”. In: Ball, M.J., M.R. Perkins, N. Muller and S. Howard (eds.), The handbook of clinical linguistics. Malden: Wiley-Blackwell. 412-422. 
Oliveira, C., M. Lousada and L.M.T. Jesus. 2015. "The clinical practice of speech and language therapists with children with phonologically based speech sound disorders". Child Language Teaching and Therapy.

Preston, J.L., M. Hull and M.L. Edwards. 2013. "Preschool speech error patterns predict articulation and phonological awareness outcomes in children with histories of speech sound disorders". American Journal of Speech-Language Pathology 22(2). 173-184.

Preston, J.L., P.J. Molfese, W.E. Mencl, S.J. Frost, F. Hoeft, R.K. Fulbright, N. Landi, E.L. Grigorenko, A. Seki, S. Felsenfeld and K.R. Pugh. 2014. "Structural brain differences in school-age children with residual speech sound errors. Brain and Language 128(1). 25-33.

Roberts, J., L. Rescorla, J. Giroux and L. Stevens. 1998. "Phonological skills of children with specific expressive language impairment (SLI-E): Outcome at age 3". Journal of Speech, Language and Hearing Research 41. 374-384.

Shriberg, L.D. and J. Kwiatkowski. 1982. "Phonological disorders III: A procedure for assessing severity of involvement". Journal of Speech and Hearing Research 47. 256-270.

Tkach, J.A., X. Chen, L.A. Freebairn, V.J. Schmithorst, S.K. Holland and B.A. Lewis. 2011. "Neural correlates of phonological processing in speech sound disorder: A functional magnetic resonance imaging study". Brain and Language 119(1). 42-49.

Tobin, Y. 2009a. "Comparing and contrasting Natural Phonology, Optimality Theory and the Theory of Phonology as Human Behavior". Poznań Studies in Contemporary Linguistics 45(1). 169-189.

Tobin, Y. 2009b. "Phonology as Human Behaviour: Clinical phonetics, phonology and prosody". Poznań Studies in Contemporary Linguistics 45(2). 327-352.

Wechsler, D. 2003. WPPSI-R. Escala de inteligência de wechsler para a idade préescolar e escolar. Edição revista. Lisboa: CEGOC.

Wertzner, H.F. 2000. “Teste de Linguagem Infantil na área de Fonologia”. In: Andrade, C.R.F., D.M. Befi-Lopes, F.D.M. Fernandes and H.F. Wertzner (eds.), $A B F W-$ Teste de Linguagem Infantil: Nas áreas de Fonologia, Vocabulário, Fluência e Pragmática. Carapicuíba: Pró-Fono. 5-40.

Yavas, M. and R. Lamprecht. 1988. "Processes and intelligibility in disordered phonology". Clinical Linguistics \& Phonetics 2(4). 329-345. 